\title{
Cochlear Implant: the complexity involved in the decision making process by the family ${ }^{1}$
}

\author{
Sheila de Souza Vieira ${ }^{2}$ \\ Maria Cecília Bevilacqua ${ }^{3}$ \\ Noeli Marchioro Liston Andrade Ferreira ${ }^{4}$ \\ Giselle Dupas ${ }^{4}$
}

Objective: to understand the meanings the family attributes to the phases of the decisionmaking process on a cochlear implant for their child. Method: qualitative research, using Symbolic Interactionism and Grounded Theory as the theoretical and methodological frameworks, respectively. Data collection instrument: semistructured interview. Nine families participated in the study (32 participants). Results: knowledge deficit, difficulties to contextualize benefits and risks and fear are some factors that make this process difficult. Experiences deriving from interactions with health professionals, other cochlear implant users and their relatives strengthen decision making in favor of the implant. Conclusion: deciding on whether or not to have the implant involves a complex process, in which the family needs to weigh gains and losses, experience feelings of accountability and guilt, besides overcoming the risk aversion. Hence, this demands cautious preparation and knowledge from the professionals involved in this intervention.

Descriptors: Cochlear Implantation; Deafness; Decision Making; Family; Disabled Children; Family Nursing.

\footnotetext{
${ }^{1}$ Paper extracted from master's thesis "Mobilizing to rescue the life through the cochlear implant: the experience of the cochlear implant user auditive deficient child's family" presented to Universidade Federal de São Carlos, São Carlos, SP, Brazil.

2 MSc. Scholarship holder from Fundação de Amparo à Pesquisa do Estado de São Paulo (FAPESP) process \# 2009/04332-2 and by Coordenação de Aperfeiçoamento de Pessoal de Nível Superior (CAPES).

${ }^{3} \mathrm{PhD}$, Full Professor, Departamento de Fonoaudiologia, Faculdade de Odontologia de Bauru, Universidade de São Paulo, Bauru, SP, Brazil.

${ }^{4} \mathrm{PhD}$, Associate Professor, Departamento de Enfermagem, Centro de Ciências Biológicas e da Saúde, Universidade Federal de São Carlos, São Carlos, SP, Brazil.
}

\author{
Corresponding Author: \\ Giselle Dupas \\ Universidade Federal de São Carlos. Centro de Ciências Biológicas e da Saúde. \\ Departamento de Enfermagem \\ Rod. Washington Luis, $\mathrm{km} 235$ \\ Jardim Guanabara \\ CEP: 13565-905, São Carlos, SP, Brasil \\ E-mail: gdupas@ufscar.br
}

Copyright () 2014 Revista Latino-Americana de Enfermagem This is an Open Access article distributed under the terms of the Creative Commons Attribution Non-Commercial License (CC BY-NC).

This license lets others distribute, remix, tweak, and build upon your work non-commercially, and although their new works must also acknowledge you and be non-commercial, they don't have to license their derivative works on the same terms. 


\section{Introduction}

Studies have been undertaken about parental decision making with regard to the choice of the communication modality for deaf children ${ }^{(1-7)}$, in which medical, sociocultural, economic and bioethical aspects are analyzed(8-10).

The early diagnosis of hearing impairment (HI) demands that the parents, despite a lack of information at that moment, make a series of decisions in quick succession, which includes choosing the best intervention and treatment for their child and assessing different communication, skills development and education options $^{(11)}$. Among the available resources to treat the $\mathrm{HI}$, the cochlear implant (CI) figures as an efficient and effective for the development of deaf children's communicative skills. Through this device, the first generation of implanted children has reached linguistic and academic competency levels similar to their normal hearing peers ${ }^{(12)}$.

The CI consists of an external component located behind the ear, which captures, processes, codes the sound energy and send it to the internal receiverstimulator through radiofrequency: and an internal component surgically implanted under the skin in the mastoid bone, which has a beam of electrodes inserted in the cochlea to stimulate the hearing nerve fibers, which spreads neural impulses to the hearing area of the brain stem.

Due to the current emphasis on getting the CI as early as possible, the parents may feel that they only have a short time to make their decision ${ }^{(3,6)}$. For most parents, decision making is a difficult and stressful process due to the complexity to determine whether what they believe to be the best for their child actually is. After all, this decision is loaded with influences from parental preferences, linked with their values, beliefs, practical considerations and resource availability ${ }^{(6,13-14)}$. In addition, they need to decide without any guarantees about the level of benefit their children will receive(6).

Different aspects have influenced the parents' decision-making process on their child's implant(5,7,14-15): quality, quantity and range of information received; preliminary knowledge about CI and deafness; preference and expectations about oral and/or sign language development; bioethical aspects (child's opinion, deaf identity and culture, social representation of impairment); preservation of residual hearing due to the expected development of new technologies ${ }^{(5,7)}$; daily activity constraints and low effectiveness of CI in some cases $^{(7)}$; care and financial costs of the device and postimplant (re)habilitation(5). The most difficult aspect for parental decision making is the fear of the risks involved in the surgical procedure and possible complications, factors that cause stress, anxiety, fear, insecurity and anguish in the parents ${ }^{(16-18)}$. This concern was similar in hearing and deaf parents and in unilateral or bilateral implant procedures ${ }^{(2,5,7)}$.

On the opposite, parents reported easy and rapid decision making on the $\mathrm{CI}$ because they believed that there was no better option for their child(3,6). In another study, it was shown that some parents believe they do not take away their children's right to choose when they decide to have the implant, as this decision can be discussed with their children as they grow older, granting them the option to remove the device ${ }^{(7)}$.

Nowadays, bilateral implants have become a highly recommended option. Thus, the parents need to decide not only on whether to have the implant or not, but also whether the implant will be bilateral, and whether it will be sequential or simultaneous ${ }^{(6,19-20)}$. As opposed to studies that presented parental decision making as a very hard process for parents whose children had their first implant, authors reported relative ease to decide on having an implant in their child's other ear, in a simple and rapid manner. This decision was influenced by the knowledge gained about neuroplasticity, binaural hearing and benefits of bilateral implants (better understanding of speech in case of noise and better ability to locate the source of the sounds, having a back-up device and maximization of the potential through this technology) (2).

The decision process in favor of the CI has also shown differences between hearing and deaf parents, as the latter do not perceive their child's deafness as a tragedy or that (s)he needs medical treatment. Deaf parents frequently prioritize the deaf identity and culture, sign language and ethical issues when making their decision, granting limited priority to the development of spoken language and oral communication skills ${ }^{(4-5)}$.

Contributing to the understanding of how the parents make a decision can provide further clarifications to the professionals and empower them in order to better support them in this difficult and stressful process.

Therefore, the objective in this study was: to understand the meanings the family attributes to the different phases involved in the decision-making process on a cochlear implant for their child. 


\section{Methods}

In this qualitative research, Symbolic Interactionism (SI) (21) and the Grounded Theory (GT) (22) were used as the theoretical and methodological framework, respectively. These frameworks permit understanding the meanings the family attributes to the different situations in the decision making process on the child's CI. Semistructured interviews were used for interaction and data collection with the families. The project received approval from the Research Ethics Committee of the University of São Paulo Rehabilitation Hospital for Craniofacial Anomalies (HRAC/USP), Opinion 182/2009-SVAPEPE-CEP. Next, after the reading and explaining of the Informed Consent Form to the participants (in compliance with National Health Council Federal Resolution 196/96), each family member signed a form and received a copy, while the researcher filed the other copy.

The research subjects were families of hearingimpaired children who used a cochlear implant and were attended at the Audiology Research Center (CPA) of HRAC/USP. The families were selected based on a list the coordination of the implant center made available. The child had to use the CI for at least one year, be enrolled in primary education and live in the state of São Paulo. In addition, the proximity of the cities between the families and the researcher was considered, with a view to the feasibility of the study.

The interviews were held between September 2009 and October 2010. We asked the families: "What was it like for you to decide on the cochlear implant?". Starting with this question, others were asked to further elaborate the theme. Each family was interviewed at home, as the proposal was to join as many members as possible, so that the data would represent different perspectives on the family experience. The interviews were recorded and fully transcribed; in line with the premises of GT, the data were collected and analyzed at the same time, using the data coding and categorization process and the understanding of the findings.

\section{Results}

Nine families participated in the study, totaling 32 family members (Figure 1 ).

\begin{tabular}{|c|c|c|c|c|}
\hline \multirow{2}{*}{$\begin{array}{l}\text { Identification of the family: } \\
\text { participating members }\end{array}$} & \multicolumn{4}{|c|}{ Identification of the child using the Cochlear Implant (CI) } \\
\hline & Gender & Etiology & Birth date & $\begin{array}{l}\text { Date of } \mathrm{Cl} \\
\text { surgery }\end{array}$ \\
\hline Family 1: Mother, Child, Brother & Male & Congenital deafness & 06/02/2001 & 04/07/2003 \\
\hline Family 2: Father, Mother, Child & Female & Genetic etiology & $09 / 11 / 2003$ & $11 / 25 / 2004$ \\
\hline Family 3: Father, Mother, Child & Female & Congenital deafness & $11 / 13 / 2002$ & 09/24/2004 \\
\hline Family 4: Father, Mother, Child & Female & Pneumococcal meningitis (2007) & 09/15/2001 & $11 / 30 / 2007$ \\
\hline Family 5: Mother, Maternal grandmother, Child & Male & Acquired deafness & 09/19/2002 & 03/19/2004 \\
\hline Family 6: Father, Mother, Child & Female & Unknown etiology & 09/15/1998 & 06/30/2005 \\
\hline Family 7: Father, Mother, Child, Sister & Female & Maternal rubella & $04 / 23 / 2001$ & 05/06/2004 \\
\hline Family 8: Father, Mother, Child, Cousin and Uncle & Female & Auditory neuropathy spectrum & 06/04/1999 & $11 / 28 / 2003$ \\
\hline Family 9: Father, Mother, Brother, Aunt, Family friend & Female & Unknown etiology & 12/22/1998 & $04 / 26 / 2002$ \\
\hline
\end{tabular}

Figure 1 - Identification of interviewed families and characterization of implanted children. Bauru, SP, Brazil, 2010

In view of the impacting situation of having their child's HI diagnosis confirmed, the family, like other families that experience chronic conditions in childhood, desperately looks for a solution to the situation. In this search movement, and not satisfied with the results of the therapeutic resources presented thus far, the family keeps on looking and ends up discovering the CI. Then, a new situation holds the family's attention: the complex decision on whether to have the child's implant. This situation demands that the team carefully and appropriately prepares the family, with experience exchange, organization of thoughts and feelings, courage to overcome the fear, and responsibility sharing among those responsible for the decision, which will exert a determining influence on the child's future. The interviewed families picture this process in the theme Clinging to the Hope of Implanting, discussed at four times: Feeling welcomed in the preparation for the child's implant, Waiting to know whether the child is a candidate for the implant, Suffering because of having to make a decision and Experience exchange, strengthening the decision. 


\section{Feeling welcomed in the preparation for the child's implant}

The preparation process for the $\mathrm{CI}$ involves multiple facets. It involves sharing information with the family, granting psychological support, assessing whether the child attends to the eligibility criteria for the implant and analyzing the family context and the future conditions to keep up the rehabilitation process. The initial shock is unavoidable due to different information, experiences from other families going through a similar situation and context with the unknown technology of the CI system.

The hearing specialist played a tape with the surgery, on how one of the first implants was done so that, when we were called, the family was already prepared to accept everything (MOTHER5).

When you discover it, you also get shocked by loads of wires, with a lot of things, we think we won't remember all of the information needed (MOTHER2).

The family feels welcomed as a result of the care provided because the professionals are prepared. The team uses different resources: therapeutic toys, audiovisual recording, individual and group orientations, contact with other families and psychological support. But nothing causes more impact and positive influence than being able to closely witness the results of implanted children.

They said I needed to go there to see everything. Then they showed a tape, a recording and it showed the phases of a small child, who grows up and so. Then I said: 'Now my daughter will talk!' (FATHER3). He (father) cried while watching the tape (MOTHER3).

The orientation at the operating room of the center is very good because [...] you have contact with a doll all wrapped up, with a syringe, for the child to get an idea, not get scared... And psychologically for the parents, who start to see pictures, get psychological orientation [...] it was very good for us to be able to decide (FATHER2).

This infrastructure and the preparation of the team surprise the family, which arrives at the institution prejudiced, thinking that, because it is a public health service, care may be bad and waiting times too long.

We didn't leave Bauru with any doubt. They did the same test with different devices, on different days, we didn't leave without the diagnosis and treatment. Because, when we left here to get treated in the SUS, our hair stood on end, we imagined 'there will be a queue and bad care'. That's the only thing we have as a reference. And we got there [...] we felt enchanted because we had never seen treatment like that, mommy here, daddy there, this thing of seeing a psychologist (MOTHER2).

\section{Waiting to know whether the child is a candidate for the implant}

After the evaluation and preparation period for the $\mathrm{CI}$, one again, the family goes through intense anxiety: knowing whether the child attends to the prerequisites, when (s)he will be selected and regarding the decision to consent with the child undergoing the surgery or not. Various factors facilitate or hamper the decision process and lead to the refusal of or consent with the surgery. The consulted families indicate two possibilities: Anxiously awaiting the child's turn or Being afraid of implanting. No matter the answer, an action/reaction is triggered which interferes in the family functioning, demanding a reformulation of the meanings in order to continue.

In principle, the chance of implanting seemed farfetched, as families that have already gone through the process comment on how difficult it was for them due to the great demand for this resource and the fact that the specialized center attends to people from all over the country. In most cases, choosing a private service is beyond their reach, as the cost of the procedure is high. Another situation that arouses expectations is the perception that the implant program is interrupted by the lack of public funding and the knowledge that the child is almost reaching the age limit when the implant is indicated most.

We were in no conditions to do it, pay it, buy it [...] we kept waiting for the government funding, one year went by and he was waiting. It was so difficult, so difficult, so difficult [...] it seemed as if he would not make it (MOTHER1).

Between the ages of two and three they never called on us again. It was when I was going to call because, as there's an age limit and she was already completing 3 years [...] I thought they had detached here, and that she didn't have a chance of having the implant anymore. Because it's very expensive and there are a lot of children waiting (MOTHER7).

As time goes by, in cases of post-lingual deafness, the child starts to suffer from speech alterations and isolation by peers. This fact makes the child feel impatient, due to not understanding what the people are saying and because (s)he wants to hear again.

And she (child) wanted to. She used to sit on the couch and asked, every day 'Dad, make me hear', every day. She was already stopping to speak, swallowing letters, too nervous, hit me, hit the mother, and we were trying to be patient. She only did what she wanted (FATHER4). Because I didn't know what to do, I got angry (CHILD4).

The despair takes over. Then I said: this implant is the only salvation. Because the phase was starting in which other 
children would isolate here because she doesn't talk. I think that's the saddest thing for a parent (MOTHER7).

On the other hand, for some families, knowing that the child is a candidate for the implant means the certainty that the problem is more severe. They would like to hear that a conventional hearing prosthesis is enough, as the CI is only accomplished in cases of severe and deep deafness, and being classified as a candidate means having a high HI. Deciding on the procedure may seem like sentencing the child to the obligation to use a device for the rest of his/her life, and imposing limits due to the internal electromagnetic component that restricts and modifies the access to certain places and the performance of activities and procedures.

We wanted to hear that she wasn't a candidate, that the device would be sufficient. We didn't want to hear that it was deep, that she'd have to take the surgery (FATHER3).

At first, according to what the other mother said, he could not put his head on a steel chair or the antenna would stick, couldn't pass by a bank door, near the microwave, so that caused a lot of fear (MOTHER7). I thought: 'the world is getting modernized, increasingly computerized, everyone has a microwave, she'll have to get into a bank, open a bank account [...] It seems the device itself is outdated, it will delay her life. There's something wrong, we're in 2009 and the device seems so outdated?! (FATHER7).

One of the partners' difficulty to apprehend the information the team transmits or not having the opportunity to accompany the child to the transplant center is a factor that hampers the decision process in favor of the surgery.

It took time to do it because of me. I didn't want to authorize it. I didn't go for the tomography, nor the resonance because I was afraid she would do it. I was already scared of what had happened to her, then they talk about having a surgery 'My daughter is going to hospital again, suffer again' (MOTHER4).

As I used to go more, because his job wouldn't allow, I saw what an implant was. I kept watching implanted children, how they developed; as the father couldn't go, he definitely didn't want it (MOTHER3).

When the fear of the risk becomes bigger than the envisaged benefit, the family prefers the child alive and deaf to the possibility of losing him/her in a surgery. Hence, the family may not schedule the tests needed, become closed to the solution of doubts, in a way also because the suffering experienced since the discovery of the HI has not been overcome.

At that time I didn't want it that much because (cries) we're afraid it won't work, but then he went with me and signed there immediately (MOTHER8). The doctor said it was difficult for this kind of surgery to go wrong, but they did not discard the possibility that it could go wrong, that it could cut some nerve and lose movements on one side of the face. He said it had never happened, but that it could happen. So there was this doubt (FATHER8).

One of the partners' delay to authorize the surgery postpones the process, causes conflicts with the team, aggravates the disequilibrium in the family and puts an emotional and physical burden on the family. The member most involved in the implant process feels incapable and afraid of deciding alone because this means being accountable for anything that may happen to the child and, worse, carrying the feeling of guilt for the rest of one's life.

I haven't decided until today [...] I discussed it with the social worker, with the psychologist. It's my daughter, I decide (MOTHER4). From the start, she said 'I won't do it'. She did not sign anything, I signed everything (FATHER4).

It was the best thing he went on the day of the surgery because, when the doctor asked, I got kind of and he said: 'If she does not sign I will. We came here for this, we knew this was the end. So, if the end is there, I sign' (MOTHER8).

The family also ends up having contact with others who decided not to have the implant. In addition, when the implant is done in older children, they may refuse it, mainly due to esthetic reasons, which are enhanced during adolescence.

There's a girl who had an implant when she was 10 years old, but against her will. The mother had the opportunity to have her operated on when she was little but, as she did not know anyone, she was very scared that things would happen to her daughter. The mother's kind of overprotective. Se truly regrets not having done this surgery when her daughter was small because today she's kind of revolted about this implant [...] There's another girl at her school aged 16 years who had the opportunity to do it and said 'I don't want that horrible thing in my head' (MOTHER7).

\section{Suffering because of having to make a decision}

The family suffers due to the feeling of investing in their child's life without any guarantee. Taking the child to the operating room is the act that concretizes the decision. It is a very difficult moment because their fears flourish and they feel anguished because they do not know whether they made the right decision. This moment involves reflection, reliving a whirlwind of thoughts and feeling and remembering the informed risks. As it is the family that decides for the child, the fear exists that (s)he will question this decision in the future and will react negatively, wishing (s)he had not 
done the surgery or having had the opportunity but without the parents' consent.

The most difficult part of it all, except for the diagnosis, is the moment when you have to take your child for the surgery. Because the hearing impairment is not a disease the doctor comes up to you and says 'either you operate or your child is going to die', without an option. He will not hear, but he'll live. It is very difficult because the option is ours, she couldn't know yet. We decided on her behalf without knowing whether, later, she'll question 'Why didn't you let me choose? I wanted to be deaf, I didn't want to use the aid'. So we did something on our own, thinking it would be better for her, but only time will tell (MOTHER2). If something goes wrong we'll carry that for the rest of our lives. We could have avoided it if we hadn't chosen the surgery. She'd be deaf but she'd be normal. Normal meaning being alive. [...] taking risk and causing sequelae or something irreversible, that fear is complicated for us parents (FATHER2).

I thought like: 'when she's 18 and does not want it, then it will be her option and not mine. I've done my duty as a mother (MOTHER6).

When the parents' decision is not made jointly or diverges, feelings of guilt, affliction and anger are experienced. Making a decision against the other person's will means assuming the risks and consequences alone. And, for who's in that position, that is extremely anguishing.

I had already made the decision, then I arrived and said: 'look, we can't wait anymore, will you allow her to do it or not'? I think she should do it, she's already there. I couldn't make this kind of decision alone. If something happened, I'd be sort of responsible for the rest of my life. And he (husband) said: you can take her (MOTHER7). Thanks God, because I decided. For me it was easier because she accompanied, because my job was very busy. She received the calls and the letters and then transmitted everything to me (FATHER7).

I only cried, from 7 till 11:30h (MOTHER4). I told everyone she caused more work than the daughter. When she got in to have her hair cut, she didn't look at our faces, she got very angry. If she could she'd killed me (daughter smiles a lot). After I dropped her off inside the operating room and got back, she (wife) fainted, asking to get her out of there. Then it struck my conscience 'did I do the right thing?'. Then it started to take time, and time, and time (FATHER4). Today I thank him too, because at that time I threw at him 'if it doesn't work out, if something goes wrong, it's your fault, it's your responsibility' (MOTHER4).

\section{Experience exchange, strengthening the decision}

The professionals' orientations and the contact with implanted children during the preparation phase greatly cooperate to strengthen the decision making, help to weigh risks and benefit and to decide to take the risk. Sometimes, it is necessary to let time go by in order to organize and consolidate one's ideas and feelings and be able to decide more calmly.

I thought 'Let's say I change my mind until then [...] who guarantees that until then I won't start to see the good things of the implant?!' (MOTHER7). I was watching TV and the physician from the center came by, because it's rare for something about implants to be transmitted. Afterwards I went deeper, got further knowledge, then I accepted it (FATHER7).

I accepted it with all my strength the day the hearing therapist said, then I reminded it and what remained was 'think that today there's something good for your child, and when he's older, if you don't let him have this implant he'll know that opportunity existed. He won't blame you, but he'll say: oh dear, mom, when I was little I had this chance to do it'. I was scared, but she worked with me and I ended up accepting it (MOTHER5).

For the family, there is nothing stronger to decide in favor of the surgery than preliminary contact with a child with a cochlear implant. When the results witnessed are positive, the expectations and hopes increase.

What made it easier to decide was to see $T$.'s gain. I believe that was the main factor. I had a child close to me, as an example. The difference was that she was using the hearing aid while T.'s was implanted. Each week, I saw her at the therapy room with a novelty, with gains and gains (MOTHER7).

Nevertheless, the family also experiences children with less positive results in the cochlear implant procedure, triggering some disappointment and frustration, but at the same time serving as an alert regarding the possibilities inherent in each child.

At the time, we had contact with children who had the implant when they were older. As there were few developed children, we got disappointed because we thought we'd get the implant and would leave hearing, develop like a hearing child. Then we saw children who didn't talk yet two or three years after the implant. And then we: 'she won't talk'. We left disappointed because [...] the large majority, who was hearing impaired from birth, talked little. For them, the development was very weak (FATHER6).

During the surgery, waiting for news about the child's health condition creates anguish. The tension only stops when the family has the child in their arms again. The relief of having this phase end is prominent, and knowing that the results were positive is gratifying for the family and the health team. Then, this becomes a day of rejoicing, of victory and conquest, and the family feels relieved because of the opportunity to have done something for the child. 
But thanks God the day of the surgery came. Then I said 'I can't believe it'! (MOTHER1).

The tape I watched scared a little, because it even isn't like that anymore. At that time, I kept on imagining them cutting my son's head. I remember that, when he got into the operating room it was 7 o'clock, until they shave the head you think 'My God'! It took time for her to get out [...] She got out around $13 \mathrm{~h}$ (MOTHER5).

Because we were with a lot of people who were doing facial reconstruction inside the hospital and they called everyone and we ended up alone in the room. And it took time. Then they called me on the phone, it almost killed me (child's laughs). But it was to inform that they thought they would be able to place a 6-electrode array, and they placed 24. They put in everything! They were more satisfied than us because they accompanied everything that happened. It were four and a half hours of surgery but it was, oh dear, excellent (FATHER4).

\section{Discussion}

The decision to get the implant for the child depends on facilitating and hampering elements that lead to the family's refusal or consent with the surgery. Despite the team's preparation, the family's decision process is complex and involves constant and intense moments of reflections about the decision made, due to questions about the choice made. The internal conversations are difficult for the people and entail meanings that involve responsibility, unpredictability and uncertainty.

In principle, the family may hesitate to agree with the surgery in some circumstances: when the fear of the risks is greater than the benefit envisaged; in case of a knowledge deficit; knowing that the electromagnetic device will restrict some of the child's activities and; that the decision may arouse future questions about the decision made, whether in favor or against the implant. In line with other authors, in this study, the families were concerned with the visibility of the CI's external part ${ }^{(23)}$ and, for some parents, starting to use the hearing device seems to "condemn" the child because it makes the HI visible(24).

During the team's preparation, the parents feel anxious to comply with the criteria to have their child chosen as an implant candidate, and afraid because of the risks involved. Some parental beliefs may speed up the decision process, but speeding up the process may not always lead to positive results. Parents can suffer from feelings of remorse, displeasure, regret and grief when the decision is rushed ${ }^{(25)}$. Even one year after the $\mathrm{CI}$, some families may still feel anxious because of the possibility that the child will blame them in the future because of the choice made ${ }^{(16)}$.

Therefore, during the preparation phase for decision making, it is crucial to work with the parents on the expectations and feelings of accountability, guilt and fear because of possible surgical risks ${ }^{(25)}$. Preparing the child to receive the $\mathrm{CI}$ should grant the opportunity to get familiar with situations it will go through in the surgical process, so as to minimize the insecurity and fear of the unknown. The use of playful material, therapeutic toys, contact with hospital material and with a replica of the CI's external part, dramatization of the hair cut and dressings have been well accepted(23).

Some parents experience difficulties to select the best conduct to take and need help to analyze the information and experiences associated with the choice they will make, as well as objective and impartial assistance to contextualize the risks and benefits ${ }^{(25)}$, in order to understand the advantages and disadvantages of the $\mathrm{CI}^{(6)}$. The results found show that the families felt understood and welcomed by the professionals from the implant center. They emphasized the diversity and quality of the resources the team uses and, mainly, the access to information, so that they find hope, strength and motivation to continue.

When one of the partners does not agree to authorize the surgery, this also causes emotional and physical stress in the member who is more engaged in the process. That is the case because assuming the responsibility alone means assuming any misfortune that may arise and, worse, carrying the feeling of guilt across the lifetime. Like in other studies, in families of separated parents, divergences may emerge in the decision, worsening the coping with the situation(26). In cases of deafness due to meningitis, the time to decide on the implant may even be shorter, due to the possibility of cochlear osteoneogenesis, which can make the insertion of the electrodes impossible. The shorter time to elaborate the facts increases the family's anxiety ${ }^{(17)}$.

The waiting time for the center's results about the assessment of the child's candidature for the implant was indicated as a very difficult time interval(5). The moment of the surgery, on the other hand, involved biased feeling: happiness about the opportunity to get the implant and fear because of the decision made. The support at this moment can derive from religion, the knowledge gained so far, and from the opportunity to accompany the child for as long as allowed(17).

To make the decision, the parents use and consult different information sources ${ }^{(2-3,5-6,11)}$ : health 
professionals and the team of CI programs; other families going through a similar situation; deaf people using a CI or not; teachers; communication means; sites, leaflets, audiovisual material and support groups for parents of deaf children. This is in accordance with our findings. This information and mainly the contact with implanted children with good auditory performance positively influenced the parents' decision in the presented study. The information about the high usage rate of the device among implanted children can also play an encouraging role in decision making; after all, significant levels of non-use would indicate high rates of dissatisfaction among the users(27).

Although the parents make the decision, the literature shows that other relatives, mainly the grandmothers, can exert strong influence(16).

The time needed to cope with the feelings varies for each family, demanding respect for the decision process. In that sense, it was crucial: to discuss and determine the parental ambition and desires; provide impartial, comprehensive written and oral information; emphasize the new skills and knowledge learned, so that the family members can have expectations in accordance with the reality ${ }^{(18,25)}$. The decision making will be more qualified the better the clinical information available, attending to variations in individual circumstances. The family members should never be left out of this decision ${ }^{(28)}$.

Little has been described in the literature about nurses' activities in auditory health with regard to the treatment of CI users. Nevertheless, a wide activity area exists for nurses together with the multidisciplinary team ${ }^{(29)}$, in the execution of evaluation, selection, indication and preparation activities for the decision about the $\mathrm{CI}$; in intraoperative care; in postoperative orientations; in the accompaniment to periodical returns to the $\mathrm{CI}$ center (identification of parental overprotective behaviors and dependence of the child, attempting to develop their self-care with their CI; awareness-raising of the family about its role and importance in the interaction process and in stimulating the child; identification of difficulties in the school context together with other professionals and participation in support groups for families and individuals with $\mathrm{HI}$ and $\mathrm{CI}$ users.

\section{Conclusion}

The results obtained made it possible to understand the meanings the family attributes to the different phases involved in the decision process about getting a CI for their child. Lack of knowledge, difficulties to contextualize benefits and risks, the restrictions the electromagnetic device causes for CI users and the fear of the decision made and its long-term repercussions are factors that hamper the parents' decision process; as well as the fact that the experiences deriving from the interactions with health professionals, implanted children and their relatives helped the parents to make the decision to permit the implant.

The health professionals need to discover the family values and beliefs, provide systematic, flexible and impartial orientations and information to help them gain self-confidence and define the situation.

Studies that explore the decision process to get a bilateral implant and in patients of other ages are needed to investigate how the experience takes place in these cases; as well as how other variables (gender, education, socioeconomic and cultural condition) interference in decision making on the $\mathrm{CI}$.

\section{References}

1. Decker $K B$, Vallotton $C D$, Johnson HA. Parents' communication decision for children with hearing loss: sources of information and influence. Am Ann Deaf. 2012;157(4):326-39. Disponível em: http://www.ncbi. nlm.nih.gov/pubmed/23259352

2. Fitzpatrick EM, Jacques J, Neuss D. Parental perspectives on decision-making and outcomes in pediatric bilateral cochlear implantation. Int J Audiol. 2011;50(10):679-87. Disponível em: http://www.ncbi. nlm.nih.gov/pubmed/21812634

3. Punch R, Hyde MB. Communication, psychosocial, and educational outcomes of children with cochlear implants and challenges remaining for professionals and parents. Int J Otolaryngol. 2011;2011. Article ID 573280. 10 p. doi:10.1155/2011/573280. Disponível em: http://www. ncbi.nlm.nih.gov/pubmed/21904554

4. Hardonk S, Daniels S, Desnerck G, Loots G, Van Hove G, Van Kerschaver, et al. Deaf parents and pediatric cochlear implantation: an exploration of the decision-making process. Am Ann Deaf. 2011;156(3):290-304. Disponível em: http://www.ncbi.nlm.nih.gov/pubmed/21941879

5. Hardonk S, Bosteels S, Desnerck G, Loots G, Van Hove G, Van Kerschaver E, et al. Pediatric cochlear implantation: a qualitative study of parental decisionmaking processes in Flanders, Belgium. Am Ann Deaf. 2010;155(3):339-52. Disponível em: http://www.ncbi. nlm.nih.gov/pubmed/21138046 
6. Hyde M, Punch $R$, Komesaroff $L$. Coming to a decision about cochlear implantation: parents making choices for their deaf children. J Deaf Stud Deaf Educ. 2010;15(2):162-78. Disponível em: http://www.ncbi. nlm.nih.gov/pubmed/20139157

7. Okubo S, Takahashi M, Kai I. How Japanese parents of deaf children arrive at decisions regarding pediatric cochlear implantation surgery: a qualitative study. Soc Sci Med. 2008;66:2436-47. Disponível em: http://www. ncbi.nlm.nih.gov/pubmed/18362048

8. Miziara ID, Miziara CSMG, Tsuji RK, Bento RF. Bioethics and medical/legal considerations on cochlear implants in children. Braz J Otorhinolaryngol. 2012;78(3):70-9. Disponível em: http://www.scielo.br/scielo.php?pid= S1808-86942012000300013\&script=sci_arttext\&tlng=en

9. Kermit P. Choosing for the child with cochlear implants: a note of precaution. Med Health Care Philos. 2010;13(2):157-67. Disponível em: http://www.ncbi. nlm.nih.gov/pubmed/20155398

10. Hintermair M, Albertini JA. Ethics, deafness, and the new medical technologies. J Deaf Stud Deaf Educ. 2005;10(2):184-92. Disponível em: http://jdsde. oxfordjournals.org/content/10/2/184

11. Li Y, Bain L, Steinberg A. Parental decision making and the choice of communication modality for the child who is deaf. Arch Pediatr Adolesc Med. 2003;157(2): 162-8. Disponível em: http://www.ncbi.nlm.nih.gov/ pubmed/12580686

12. Tanamati LF, Costa OA, Bevilacqua MC. Longterm results by using cochlear implants on children: systematic review. Int Arch Otorhinolaryngol. 2011;15(3): 365-75. Disponível em: http://www.scielo.br/scielo. php?pid=S1809-48722011000300016\&script=sci_arttext 13. Li Y, Bain L, Steinberg A. Parental decision-making in considering cochlear implant technology for a deaf child. Int J Pediatr Otorhinolaryngol. 2004;68(8):102738. Disponível em: http://jdsde.oxfordjournals.org/ content/15/2/162.full

14. Couto MIV, Carvalho ACM. Factors that influence the participation of parents in the oral rehabilitation process of children with cochlear implants: a systematic review. CoDAS [Internet]. 2013;25(1):84-91. Disponível em: http:// www.scielo.br/scielo.php?script=sci_arttext\&pid=S231717822013000100015\&lng=en\&nrm=iso\&tlng=en

15. Peñaranda A, Suárez RM, Niño NM, Aparicio $M L$, García JM, Barón C. Parents' narratives on cochlear implantation: reconstructing the experience of having a child with cochlear implant. Cochlear Implants Int. 2011;12(3):147-56. Disponível em: http://www.ncbi. nlm.nih.gov/pubmed/21917202
16. Incesulu A, Vural M, Erkam U. Children with cochlear implants: parental perspective. Otol Neurotol. 2003;24(4):605-11. Disponível em: http://www.ncbi. nlm.nih.gov/pubmed/12851553

17. Mussa C, Bruscato WL, Iervolino SMS, Campos CAH. A atuação do psicólogo durante o processo de implante coclear: relato de caso. Pediatr Mod. 2010;46(1):26-30. Disponível em: http://bases.bireme.br/cgi-bin/wxislind. exe/iah/online/?IsisScript=iah/iah.xis\&src=google\&bas e $=$ LILACS\&lang $=$ p\&nextAction $=$ Ink\&exprSearch $=54158$ 2\&indexSearch $=$ ID

18. Yamanaka DAR, Silva RBP, Zanolli ML, Silva ABP. Implante coclear em crianças: a visão dos pais. Psicol Teor Pesqui. 2010;26(3):465-73. Disponível em: $\quad$ http://www.scielo.br/scielo.php?pid=S010237722010000300009\&script=sci_arttext

19. Galvin KL, Leigh JR, Hughes KC. How we do it: clinical management of the child receiving a second, bilateral cochlear implant. Cochlear Implants Int. 2009;10(2):84-91. Disponível em: http://www.ncbi. nlm.nih.gov/pubmed/18949762

20. Ramsden JD, Papaioannou V, Gordon KA, James AL, Papsin BC. Parental and program's decision making in paediatric simultaneous bilateral cochlear implantation: Who says no and why?. Int J Pediatr Otorhinolaryngol. 2009;73:1325-8. Disponível em: http://www.ncbi.nlm. nih.gov/pubmed/19616316.

21. Charon JM. Symbolic interacionism: an introduction, an interpretation, an integration. 9th.ed. New Jersey: Prentice Hall; 2007. 241 p.

22. Strauss A, Corbin J. Pesquisa qualitativa: técnicas e procedimentos para o desenvolvimento da teoria fundamentada. 2nd ed. Porto Alegre: Artmed; 2008. 288p. 23. Yamada MO, Bevilacqua MC. O papel do psicólogo no programa de implante coclear do Hospital de Reabilitação de Anomalias Craniofaciais. Estud. psicol. (Campinas). 2005;22(3):255-62. Disponível em: http://www. scielo.br/scielo.php?script=sci_arttext\&pid=S0103166X2005000300004

24. Caldas FF, Lemos AB, Tschiedel RS. O envolvimento do pai no processo de (re)habilitação auditiva de seu filho deficiente auditivo. Comun. ciênc. saúde. 2009;20(1):17-28. Disponível em: http://bases.bireme. br/cgi-bin/wxislind.exe/iah/online/?IsisScript=iah/iah.xi $\mathrm{s} \& \mathrm{src}=$ google\&base $=$ LILACS\&lang $=\mathrm{p} \&$ nextAction $=\operatorname{lnk} \&$ exprSearch $=540309$ \&indexSearch $=$ ID

25. Duncan J. Parental readiness for cochlear implant decision-making. Cochlear Implants Int. 2009;10 Suppl 1:38-42. Disponível em: http://www.ncbi.nlm.nih.gov/ pubmed/19230035 
26. Alves JG. A doença aguda e a família. In: Mello Filho J, Burd M. Doença e Família. São Paulo (SP): Casa do Psicólogo; 2004. p. 245-9.

27. Archbold SM, Nikolopoulos TP, Lloyd-Richmond $\mathrm{H}$. Long-term use of cochlear implant systems in paediatric recipients and factors contributing to non-use. Cochlear Implants Int. 2009;10(1):25-40. Disponível em: http:// www.ncbi.nlm.nih.gov/pubmed/18979457

28. Campos DCF, Graveto JMGN. The role of nurses and patients' involvement in the clinical decisionmaking process. Rev. latinoam. enferm. 2009;17(6): 1065-70. Disponível em: http://www.scielo.br/scielo. php?pid=S0104-11692009000600021\&script=sci_arttext 29. Vieira SS, Bevilacqua MC, Ferreira NMLA, Dupas G. Discovery of hearing impairment by the family: seeing an idealized future collapse. Acta Paul Enferm. 2012;25(Número Especial 2):82-8. Disponível em: $\quad$ http://www.scielo.br/scielo.php?pid=S010321002012000900013\&script $=$ sci_arttext 